\title{
«PARLAMENTO ABIERTO»: UNA VISIÓN DESDE \\ LOS PRINCIPIOS DE FUNCIONAMIENTO \\ DE LAS CÁMARAS PARLAMENTARIAS'
}

\section{Open Parliament: A view inspired by the working principles of the Parliamentary Chambers}

\author{
ELVIRO ARANDA ÁLVAREZ \\ Universidad Carlos III de Madrid \\ elviro.aranda@uc3m.es
}

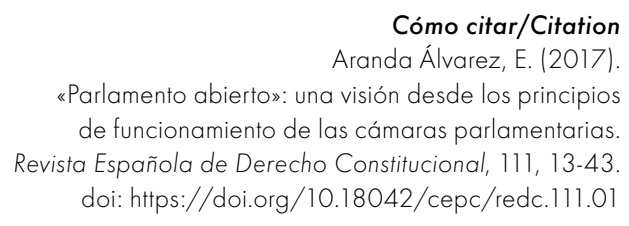

Resumen

Las nuevas tecnologías de la información y la comunicación (TIC) son un buen instrumento para fortalecer los principios que caracterizan el trabajo del Parlamento —representación, control, participación, deliberación, colaboración y publicidad-. Este artículo analiza cómo dichas tecnologías pueden introducir novedades muy importantes tanto en la organización parlamentaria como en el funcionamiento de sus órganos. Muestra de ello es que tanto la representación como la legitimación de órganos del Estado pueden mejorar con la incorporación de las TIC al Parlamento. Sin embargo, el Parlamento seguirá cumpliendo la misión que siempre ha tenido encomendada: expresar la voluntad popular.

1 Ponencia seleccionada por la Asociación de Constitucionalistas de España (ACE) de entre las presentadas a su XV Congreso (Universidad de León, 30-31 de marzo de 2017). 


\title{
Palabras clave
}

Parlamento; tecnologías de la información y la comunicación; representación; participación; deliberación; publicidad; colaboración.

\begin{abstract}
The new tools provided by Information Technologies (IT) can strengthen the principles on which parliamentary activities are based - representation, control, participation, debate, collaboration and public scrutiny-. This study analyses the important innovations introduced by IT in both the organization of Parliament and the procedures of its bodies. This study will show how the use of the new technologies by Parliament will improve the representative nature as well as the legitimacy of the Chambers. Within this framework, Parliament will strive to fulfit its constitutional mission: to express the will of the people.
\end{abstract}

\section{Keywords}

Parliament; new information technologies; representation; participation; debate; public scrutiny; collaboration. 


\section{SUMARIO}

I. INTRODUCCIÓN. II. UNA MIRADA AL PARLAMENTO DESDE LOS PRINCIPIOS QUE DEFINEN SU FUNCIONAMIENTO. III. EL REFUERZO DE LAS FUNCIONES PARLAMENTARIAS DE REPRESENTACIÓN Y LEGITIMACIÓN. IV. UN PARLAMENTO PARA LA DELIBERACIÓN QUE INTEGRA LA OPINIÓN DE LOS CIUDADANOS. V. UN PARLAMENTO QUE REFUERZA LA PUBLICIDAD CONVIRTIÉNDOLA EN TRANSPARENCIA. VI. UN PARLAMENTO QUE EXTIENDE LA COLABORACIÓN A OTROS ÓRGANOS DEL ESTADO E INSTITUCIONES. VII.UNPARLAMENTOQUERECUPERAELSENTIDODELARESPONSABILIDAD POLIITICA. VIII. UN PARLAMENTO QUE SE ABRE A LA PARTICIPACIÓN DIRECTA DE LOS CIUDADANOS. IX. CONCLUSIONES. BIBLIOGRAFíA.

\section{INTRODUCCIÓN}

La democracia representativa ha estado puesta en cuestión desde el mismo día en que vio la luz. Desde la advertencia que Rousseau (1982: 161) hiciera sobre la democracia de los ingleses — «El pueblo inglés piensa que es libre y se engaña: lo es solamente durante la elección de los miembros del Parlamento: tan pronto como éstos son elegidos, vuelve a ser esclavo, no es nada» - hasta los defensores de la ciberdemocracia (Masuda, 1984: 120-127; Toffler, 1989: 49-52; Tribe, 1991: 25-33; Hagen, 2000: 20-45; Van Dijk, 2013: 1-17; Bellamy, 2000: 36 y ss), pasando por aquellos (Schmitt, 2008: 22-23) que entendían que la democracia solo era posible si hay identidad entre el pueblo y los órganos políticos de decisión — «forma parte, necesariamente, de la democracia, primero, la homogeneidad, y, segundo (en caso necesario) la separación o aniquilación de lo heterogéneo»—, se han vertido muchas críticas a la democracia representativa. Sin embargo, dicha forma de organización política ha demostrado ser la mejor de las conocidas para garantizar la participación de los ciudadanos, legitimar los poderes del Estado y contribuir a una sociedad más desarrollada, generadora de alta calidad de vida para los ciudadanos $^{2}$.

Las críticas a la democracia representativa han venido unidas a las críticas al Parlamento y el parlamentarismo. También aquí, desde la encendida defensa del sistema hecha por Kelsen en los años treinta del pasado siglo, el

2 Sobre la influencia que la democracia tiene en el desarrollo económico véase Duverger (1970: 70-112); Lipset (1992: 113-150); García Pelayo, (1995: 121-150). 
Parlamento ha resistido los envites de los críticos y ha evolucionado adaptándose a los nuevos tiempos para el mejor funcionamiento de la democracia representativa (Kelsen, 1977: 48; Manin, 1998: 237-280). Más allá de la opinión que nos merezcan dichos cambios, lo cierto es que hemos atravesado por diversos periodos en los que se han ampliado o corregido las funciones del Parlamento - por ejemplo, parlamentarismo de asamblea, parlamentarismo de gabinete o parlamentarismo racionalizado-y las variaciones introducidas han servido para comprobar las posibilidades de integración del Parlamento en el sistema político ${ }^{3}$.

La aparición y desarrollo en los últimos tiempos de la tecnología de la información y comunicación (TIC) ha puesto en cuestión, nuevamente, la utilidad del Parlamento o, como poco, la forma de desarrollar su activi$\mathrm{dad}^{4}$. Parece claro que la tecnología de la información y la comunicación producirá grandes cambios tanto en la organización y funcionamiento del Parlamento cuanto en las funciones parlamentarias. Sin embargo, somos escépticos ante aquellas tesis que creen que dichos recursos tecnológicos pueden llegar a alterar la esencia misma del sistema: producir representación y que los representantes hablen en nombre del pueblo. El Parlamento y la función representativa, como señalara Kelsen (1997: 52-53) y, más tarde, Sartori (1999 y 1998) conforma una ficción politica ${ }^{5}$ que sirve para que sociedades complejas, populosas y cada día más especializadas construyan un sistema que permite a todos los individuos participar de las decisiones comunes sin tener que ocupar todo su tiempo o tener un conocimiento enciclopédico ${ }^{6}$. Por supuesto que el parlamentarismo, así como la institución parlamentaria, pueden verse mejorados con la incorporación de las

3 Sartori (2016: 132-133) nos dice que «hay por lo menos tres variedades principales de sistemas parlamentarios: en un extremo está el sistema de primer ministro o de gabinete, de tipo inglés, en que el Ejecutivo forzosamente prevalece sobre el Parlamento; en el otro extremo está el tipo francés de gobierno por asamblea (Tercera y Cuarta República) que casi impide gobernar; y a la mitad del camino entre ellos encontramos la fórmula del parlamentarismo controlado por los partidos».

4 Una buen compendio de trabajos sobre los efectos de la tecnología en la actividad parlamentaria puede consultarse en el libro coordinado por Rubio Núñez (2014). Tudela Aranda (2008: 67-94).

5 Por su parte, Pitkin (1985: 101-122) habla de representación simbólica.

6 Es la clásica posición sobre la «libertad de los modernos» que magistralmente formulara Constant en su famosa conferencia del Ateneo Real de París de 1819 «De la liberté des anciens comparée à celle des modernes», Constant (1989: 257-285). Argumentos liberales a los que habría que añadir el de la representación como forma de división especializada del trabajo de Burke (2008: 85-92). 
TIC y las oportunidades que ofrece la mayor y mejor información; sin embargo, aún parece lejano un sistema político que prescinda del Parlamento y de las funciones que tiene atribuidas.

Un planteamiento mucho más realista, que es al que se suma este artículo, es aquel que ve en las TIC un buen instrumento para fortalecer algunos de los principios que caracterizan al Parlamento - representación, participación, deliberación, colaboración y publicidad-. Dichos cambios no son poca cosa. Como veremos, introducen novedades muy sustanciales tanto en la organización (por ejemplo, en la finalidad que se le atribuye al derecho de petición y su correspondiente comisión o en el voto electrónico de los parlamentarios ${ }^{7}$ ) como en el funcionamiento (que los ciudadanos y los grupos puedan "participar» del procedimiento legislativo o la recogida de firmas en las iniciativas legislativas populares de forma electrónica). Incluso las funciones parlamentarias pueden verse muy mejoradas con la intervención de los ciudadanos, el acceso a información comprensible o la mejora de la colaboración entre instituciones. En definitiva, un Parlamento que, como en tantos otros momentos de su historia, es capaz de integrar el desarrollo tecnológico para hacer más fácil e inmediata la consecución de sus objetivos.

\section{UNA MIRADA AL PARLAMENTO DESDE LOS PRINCIPIOS QUE DEFINEN SU FUNCIONAMIENTO}

No hace falta recordar a Aristóteles y su Metafísica o a Tomás de Aquino y su Summa Theologiae para llegar a la conclusión de que adentrarnos en el conocimiento de una institución a través de los principios que la identifican nos sitúa en un terreno altamente movedizo y sometido a no pocas críticas. Prieto Sanchís (1998: 47), refiriéndose a los principios del derecho, dice de ellos que «son uno de los últimos y más vistosos artificios fabricados por los juristas — podríamos sumar también a politólogos—, capaces de servir por igual a malabarismos conceptuales que a propósitos ideológicos, de valer lo mismo para estimular una cierta racionalidad argumentativa que para encubrir las más disparatadas operaciones hermenéuticas». Por lo tanto, lo primero que debemos decir es que hemos de ser prudentes al hablar y justificar el Parlamento a través de principios. No obstante, la comprensión tanto de las instituciones políticas como de las normas que se encargan de su organización

7 Véase la Resolución de la Mesa del Congreso de los Diputados, de 21 de mayo de 2012, para el desarrollo del procedimiento de votación telemática. 
- en particular las constitucionales - mejora si se hace un ponderado uso de ellos. Tal es así que la técnica que nos acerca al conocimiento del derecho y las instituciones políticas mediante los principios siempre ha tenido una especial importancia en la teoría jurídica ${ }^{8}$. En ese sentido, ya en los ańos ochenta García de Enterría (1980: 24) nos decía que los principios jurídicos «son los únicos instrumentos disponibles para dar sentido a las instituciones y para articular éstas en el sistema general del ordenamiento" y permiten «la justificación del hecho elemental de que la interpretación de la ley escrita sea un menester técnico y no gramatical». En el mundo del Parlamento no solo sirven para facilitar la mejor integración de las normas que organizan su funcionamiento sino que muchos de ellos son, como decíamos, consustanciales a la institución (por ejemplo, representación, deliberación, publicidad o principio de las mayorías).

Esos principios definen a la institución misma, y es por ello que muchas veces cuando hablamos de "crisis del Parlamento" lo que realmente estamos diciendo es que se han quebrado dichos principios, reconocidos al Parlamento para hacer valer la democracia representativa. Lo relevante en este momento es comprobar si las TIC pueden llegar a ser un recurso que haga recobrar esos objetivos. Si el Parlamento del siglo xxi puede ser más representativo, robustecer la deliberación, mejorar la participación ciudadana, la colaboración entre instituciones y garantizar la transparencia auxiliado por las nuevas tecnologías.

\section{EL REFUERZO DE LAS FUNCIONES PARLAMENTARIAS DE REPRESENTACIÓN Y LEGITIMACIÓN}

El Parlamento sirve a la democracia porque es la institución que tiene encomendado hacer presente la voluntad popular. Da vida al sujeto político más importante de nuestro sistema y hace posible la integración de los plurales y diversos intereses presentes en la sociedad. Sin Parlamento sería muy difícil imaginar la democracia representativa. El problema que ha tenido este constructo es que con el mandato parlamentario no ha quedado claro, en la práctica, quién y qué se representa.

La regulación constitucional de la mayoría de los sistemas parlamentarios tiene un problema grave en cuanto a la comprensión del mandato parlamentario. Aunque lo entienden en su consideración más clásica —organizado en torno al diputado considerado individualmente y a la prohibición del mandato imperativo-, sin embargo no renuncian al diseño de unas Cámaras

$8 \quad$ Larenz (1994: 242 y ss); Dworkin (1995: 62-102). Sobre los principios en el derecho parlamentario véase Pendás García (1996: 217-238); Lavilla (1996: 49-66). 
parlamentarias con una organización y funcionamiento establecido para el protagonismo de los grupos parlamentarios y la dirección política de los partidos. El resultado es una situación de notable confusión: por un lado, se activan principios y normas que aseguran la autonomía e independencia del diputado individualmente considerado; por otro, se regulan procedimientos e instituciones que privilegian a los grupos parlamentarios'. La confusión está servida y ha quedado constatada en múltiples ocasiones (por ejemplo, el debate en torno al transfuguismo o las condiciones en las que los diputados ejercen la actividad parlamentaria). Una nueva regulación debería superar, en consecuencia, esta situación, no dando la victoria a un modelo sobre el otro, sino procurando integrar ambos sistemas (Garrorena Morales, 2014: 177183). Para ello, sin menoscabo de la importancia de los grupos parlamentarios, los cambios que las TIC pueden favorecer deben ir dirigidos a reforzar el estatuto del diputado, mejorando su autonomía y la transparencia y comunicación con la ciudadanía. Un diputado más responsable de su agenda política, que da cuenta y responde de su actividad de forma individual.

Pero más allá de la complejidad de la dialéctica entre diputado individual y grupos parlamentarios a la hora de entender la representación, que está en el centro de la teoría política de nuestro tiempo y que excede las pretensiones de este artículo, un Parlamento representativo debe prestar dos servicios que con dificultad cumple hoy día y que con las TIC quizás pueda conseguir ${ }^{10}$.

En primer lugar, el Parlamento debe representar a los ciudadanos y a la sociedad en su conjunto, que son los que han elegido a sus miembros y los que esperan que sus opiniones sean tenidas en cuenta a la hora de tomar las decisiones políticas. Pero tan importante como que los ciudadanos y la sociedad en general se sientan "presentes» por la acción de los representantes es que estos mantengan el contacto con aquellos. Para ello, es fundamental un Parlamento que esté abierto a la sociedad y que dé permanente cuenta de lo que hace (Aguiar de Luque, 2001: 29; Punset Blanco, 2001:10 y ss). En este sentido, la doctrina, la sociedad civil y la práctica de algunas asambleas nos

9 Hasta tal punto ha sido así que el propio Tribunal Constitucional ha llegado a decir que las retribuciones individuales que perciben los diputados no forman parte del núcleo básico del derecho de acceso y ejercicio al cargo público y, sin embargo, las asignaciones a los grupos parlamentarios sí que forman parte de ese derecho en su ejercicio colectivo; STC 36/2014, de 27 de febrero. Véase Aranda Álvarez (2015: 119164). También García Roca (1999: 295).

10 El trabajo doctrinal en esta materia ha sido muy abundante, por todos, véase Pitkin (1985); Porras Nadales (1994); Garrorena Morales (2014); Caamaño Domínguez, (1991). 
ofrecen nuevas experiencias para que con el uso de las nuevas tecnologías se logre una mayor apertura y comunicación entre el Parlamento y los ciudadanos $^{11}$. Aquí, el Congreso de los Diputados tiene mucho que hacer. Para empezar debería poner al día su página web, que resulta claramente desfasada y es poco intuitiva, con lo que mejoraría en transparencia y publicidad ${ }^{12}$. También es posible mejorar en participación ciudadana. Se podría reconvertir la Comisión de peticiones en una verdadera Comisión de participación

11 Las posibilidades de apertura del Parlamento son muchas. Algunas funcionando ya, otras en fase experimental. Por todas, véase el experimento de los «Encuentros Abiertos Digitales» en el Congreso de los Estados Unidos de América, proyecto de Lazer et al. (2009) disponible en: http://www.congressfoundation.org/storage/ documents/CMF_Pubs/online-town-hall-meetings.pdf; debates públicos temáticos en el Parlamento británico; Coleman y Blumler, (2009); Proyecto e-democracia de la Cámara de Diputados de Brasil; la Alianza para el Parlamento Abierto en México, constituida en 2014 por organizaciones de la sociedad civil y el Órgano Garante de Acceso a la Información y Protección de Datos y las instituciones legislativas. Dicha alianza aprobó una declaración de 10 principios sobre transparencia parlamentaria: 1. Derecho a la información. 2. Participación ciudadana y rendición de cuentas. 3. Información parlamentaria. 4. Información presupuestaria y administrativa. 5. Información sobre legisladores y servidores públicos. 6. Información histórica. 7. Datos abiertos y no propietarios. 8. Accesibilidad y difusión. 9. Conflicto de intereses. 10. Legislar a favor del Gobierno abierto; disponible en: www. parlamentoabierto.mx. También la Red ParlAmericas: www.parlamericas.org. En los parlamentos españoles, véase Parlamento abierto de Navarra: www.parlamentoabierto.parlamentodenavarra.es; Parlamento abierto de las Cortes valencianas: www.cortsvalencianes.es. Puede consultarse Gonzalo, http://sesiondecontrol.com/ actualidad/participacion-y-parlamento/. Muchos más ejemplos ha recopilado Vela Navarro-Rubio en su tesis, leída el 17 de noviembre de 2015 en la UCM, con el título El Parlamento abierto. La influencia de la tecnología en la evolución de la institución parlamentaria. Un estudio muy detallado de las necesidades sobre publicidad y transparencia en nuestros parlamentos ha realizado Greciet García (2012: 252). No me resisto a citar también una nueva "aportación» de la que he tenido conocimiento cuando terminaba este trabajo y que quizás pueda ser un ejemplo de un exceso en el uso de las nuevas tecnologías. Es la iniciativa de las Cortes de Aragón para hacer fichar a sus diputados para que puedan cobrar las dietas de asistencia: http://www.publico.es/politica/parlamento-aragones-sera-obligar-fichar.html.

12 Véase http://www.senado.es/web/index.html. Dichas mejoras se acompañaron de un «Plan de Comunicación On Line para el Senado de Espańa» que analiza las diferentes posibilidades de apertura a la sociedad de la Cámara y hace una propuesta que denomina Social Media Plan. Documento interno editado por el servicio de publicaciones del Senado. 
ciudadana en la que los peticionarios —individuales o colectivos - pudieran comparecer ${ }^{13}$. Por supuesto, debería mejorar en su responsabilidad respecto a los ciudadanos. El Congreso de los Diputados debe hacerse eco de las recomendaciones que la Unión Interparlamentaria formula cuando habla de una institución parlamentaria que dé cuenta de sus actividades en cuanto que órgano constitucional del Estado ${ }^{14}$. Es crucial cómo los representantes proyectan su acción política en la sociedad. Para ello, es básico seguir mejorando la publicidad parlamentaria. Necesitamos una Cámara más transparente para que todo lo que en ella se haga tenga reflejo público ${ }^{15}$. Es cierto que nuestro Parlamento funciona con la regla general de publicidad y también es cierto que son pocos los reductos de secreto o reserva. Pero se puede hacer más. Hasta ahora tenemos un modelo de "publicidad pasiva" que requiere que el ciudadano tome iniciativa para conocer lo que en el Parlamento se hace. Este sistema debe seguir en algunos ámbitos: es el caso de las publicaciones oficiales, el acceso a las Cámaras o a la documentación; pero con las nuevas tecnologías se puede organizar una "publicidad activa» ${ }^{16}$. Una publicidad que lleve al Parlamento y su actividad parlamentaria a las casas de los ciudadanos y a los terminales de los ordenadores. Todo esto, como decíamos, sin menoscabo de que en algunos casos tenga que mantenerse el secreto de ciertas actividades que puedan afectar a cuestiones de secretos de Estado,

13 En el sentido que aquí se apunta, el Grupo Parlamentarios Socialista presentó una proposición de reforma del Reglamento del Congreso en la X Legislatura: Boletín Oficial de las Cortes Generales. Congreso de los Diputados. X Legislatura. Serie B: Proposiciones de Ley. 1 de junio de 2012. Núm. 74-1.

14 Puede consultarse la Estrategia de la UIP «Mejores parlamentos para mejores democracias» 2012-2017 en http://www.ipu.org/pdf/publications/strategy-s.pdf.

15 En este sentido la Resolución de Presidencia de 2012 sobre edición electrónica de las publicaciones oficiales ha establecido que «El proceso de incorporación de las tecnologías de la información y de las comunicaciones obliga a la administración parlamentaria a dotarse de los medios y sistemas electrónicos adecuados que, a la vez que sirven para mejorar el funcionamiento interno y la gestión de los recursos, permiten hacer efectivo el derecho de los ciudadanos a relacionarse con las Administraciones Públicas utilizando medios electrónicos, según las pautas marcadas por la Ley 11/2007, de 22 de junio». Resolución de las Mesas del Congreso de los Diputados y del Senado, de 10 de julio de 2012, sobre la edición electrónica de las publicaciones oficiales de la Sección Cortes Generales.

16 Estamos pensando en el desarrollo de estrategias como las puestas en marcha en el UK Parliament con una dirección para dar cuenta de las funciones que desarrolla (Westminster, SW1A0AA, Londres, Reino Unido) y enlaces a las redes sociales donde opera (Youtube, Flickr, Twitter, Friendfeed). 
derechos de terceros o cierta confidencialidad para facilitar acuerdos parlamentarios. De todo ello hablaremos más adelante.

En segundo lugar, el Parlamento actúa legitimando la acción del resto de poderes del Estado. En las formas de gobierno de democracia parlamentaria la «legitimidad de primer nivel», al menos constitucionalmente hablando, la ostenta el Parlamento, que es el órgano resultante directamente de la voluntad de los ciudadanos. Todos los demás poderes, en especial el ejecutivo y en particular su presidente, obtienen su legitimidad democrática de la voluntad parlamentaria. Para que este proceso de legitimación no se convierta en un mero «ritual» para cumplir con los requisitos constitucionales, se debe garantizar que el Parlamento sigue contando con la necesaria autonomía del resto de poderes, pero también de «los nuevos poderes» (véase partidos políticos) que pueden dejar en mero trámite esa función parlamentaria.

Sin duda esta es una de las funciones más importantes del Parlamento en un sistema parlamentario. El momento crucial de su actuación es la investidura del presidente del Gobierno que transmite a quien va a ser el jefe del Ejecutivo la legitimidad democrática necesaria para poder desempeñar el cargo. Pero, a su vez, también crea el vínculo de fiducia de este con el Parlamento a los efectos de que se puedan poner en marcha los procedimientos de censura y, por lo tanto, de retirada de la confianza. Como decía, este es el caso más paradigmático pero no el único. El Parlamento actúa concediendo legitimidad a otros muchos sujetos que ejercerán sus cargos en distintos órganos del Estado (vocales del Consejo General del Poder Judicial, magistrados del Tribunal Constitucional, vocales de la Junta Electoral Central, etc.). En todos estos casos se necesita mucho más que la declaración de voluntad de la Cámara correspondiente. Se requiere que el procedimiento para la conformación de la voluntad política garantice un conocimiento al detalle de los candidatos propuestos y el cumplimiento de las previsiones constitucionales y legales $\mathrm{y}$, además, que se desarrolle de una forma pública que dificulte los sistemas de reparto o cuotas entre los grupos parlamentarios y obligue a llegar a acuerdos de amplia mayoría. La actual Comisión Consultiva de Nombramientos es un órgano claramente insuficiente que, aunque sirve para cumplir el requisito formal de comparecencia parlamentaria de los candidatos, no garantiza que esas designaciones se hacen en las condiciones procedimentales y de publicidad suficientes para neutralizar las pretensiones de promoción a los afines al partido (Santaolalla López, 2010: 43). Para empezar, dicha Comisión está regulada en una Resolución de Presidencia - Resolución de Presidencia del Congreso de los Diputados de 25 de mayo de 2000, relativa a la intervención de la Cámara en el nombramiento de Autoridades del Estado-, en la que se dice que es aprobada «a la espera de una regulación definitiva de esta materia 
en el futuro Reglamento del Congreso». Además, desde el punto de vista de su contenido, es bien significativo que la conformen el presidente de la Cámara y los portavoces de los grupos parlamentarios y que sus acuerdos se tomen por voto ponderado, lo que garantiza que las comparecencias se conviertan en un mero trámite para "validar» los candidatos que presentan o cuentan con el beneplácito de los grupos mayoritarios ${ }^{17}$.

En definitiva, tanto la representación política como la legitimación de los órganos del Estado pueden mejorar notablemente con la incorporación de las TIC al Parlamento: en el primer caso, porque es más fácil integrar los intereses de los ciudadanos; en el segundo, porque la publicitación de los procedimientos de designación hace que dejen de ser meros rituales sin control e inspección.

\section{UN PARLAMENTO PARA LA DELIBERACIÓN QUE INTEGRA LA OPINIÓN DE LOS CIUDADANOS}

Complemento insustituible a la representación y legitimación parlamentaria es la deliberación, como dijera Guizot (2009: 527-528), «argumentos y contraargumentos de las partículas de razón que están en los representantes y que agrupadas se convierten en poder público» ${ }^{18}$. Desde esta consideración, el Parlamento es una institución que reflejaba el pluralismo político de la sociedad - para Mirabeau, "es un mapa en pequeña escala del país»- y con ese pluralismo se hacen presentes en las cámaras los diversos intereses de la sociedad y conforman el interés general. Como dijera Burke (1996: 312-313), desde una consideración aristocrática de la representación, «el parlamento no es un congreso de embajadores que defienden intereses distintos y hostiles, intereses que cada uno de sus miembros debe sostener, como agente y abogado, contra otros agentes y abogados, sino una asamblea deliberante de una nación, con un interés: el de la totalidad». Por ello, la deliberación

17 Para comprobar la mera formalidad de su funcionamiento véase la sesión celebrada el jueves, 18 de noviembre de 2004. Comparecencia de los cinco candidatos para la elección como vocales de la Junta Electoral Central (Número de expediente 276/000003). Congreso de los Diputados. VIII Legislatura. Año 2004. Núm. 138.

18 Guizot señala como características esenciales de este sistema los siguientes puntos: i) los pouvoirs siempre estén obligados a discutir, buscando así, entre todos, la verdad; ii) que la publicidad de toda la vida estatal sitúe a los pouvoirs bajo el control de los ciudadanos; iii) que la libertad de prensa induzca a los ciudadanos a buscar la verdad por sí mismos, comunicándosela al pouvoir. Guizot (2009: 527-528). 
parlamentaria requiere mucho más que un espacio de diálogo y comprensión. Necesita de una técnica que facilite la contraposición dialéctica de intereses y que asegure la manifestación de los buenos argumentos tanto para los participantes cuanto para el público en general ${ }^{19}$. Esta es la creencia liberal en cuanto al funcionamiento del parlamentarismo: la Cámara cumple con su misión de reconocimiento del interés general si los diputados no están atados a los deseos de sus circunscripciones y participan del debate dispuestos a variar su opinión cuando se presentan mejores argumentos.

Sin embargo, en el Parlamento grupocrático contemporáneo, donde se ha asumido que las decisiones políticas que llevan a cerrar los debates parlamentarios se han tomado en otro momento, y por otros sujetos muy distintos a los que participan de la discusión en la Cámara, hace que las deliberaciones parlamentarias se desarrollen escasas de información, raquíticas en buenos argumentos y nulas de voluntad de convencimiento. El debate es una mera sucesión de discursos «enlatados» y en no pocas ocasiones leídos que, en el mejor de los casos, pretenden conseguir una frase redonda que impacte en los medios periodísticos y pueda hacer un titular o abrir una noticia televisiva (Rubio Llorente, 1997: 202). Incluso, mucho peor, como nos decía Constant (1989: 78-79) «[...] lo que entre nosotros constituye la mayor amenaza por el buen orden y la libertad, no son los excesos, ni los errores, ni la ignorancia, aunque todas esas cosas no falten; es la necesidad de presumir». Es esta una realidad que cualquier persona que siga el desarrollo de los debates parlamentarios conoce bien. Una realidad que, en parte, viene dada, como decíamos, por el llamado Parlamento grupocrático pero que, en otra parte no menos importante, es fruto de las nuevas formas para comunicar la actividad de la Cámara a la sociedad (televisión, radio e internet). Por ello, quizás sería bueno volver la vista al sentido clásico de la deliberación parlamentaria y, a partir de ahí, analizar cómo podemos hacer un aprovechamiento enriquecedor de las nuevas tecnologías para conseguir un Parlamento más deliberativo.

Recordemos: la deliberación parlamentaria hunde sus raíces en la fe que la filosofía ilustrada tenía en la razón. Para el pensamiento ilustrado la razón humana es algo objetivo y universal. Para Descartes, "la razón nos descubre verdades universales que son evidentes, innatas y que no derivan de la experiencia». Más adelante, Kriele (1980: 254) dice que es lo que nos permite hablar de un sensus comunis. Por ello, en nuestro tiempo, De Vega (1985: 56) decía que «precisamente, la opinión pública burguesa, en cuanto

19 Sobre la importancia del debate y la oratoria en la vida parlamentaria véase Cazorla Prieto (1985: 81 y ss). 
producto de la discusión libre entre particulares, se presentaría en esta óptica como el único medio de liberar a la razón individual del ofuscamiento de las pasiones y prejuicios para llegar a alcanzar ese sensus comunis que es el que se identifica con el momento de la verdad. Aparece así determinado en toda su plenitud el carácter de la discusión burguesa». Precisamente, que la «justicia y la verdad» en la lógica ilustrada solo puedan ser reconocidas mediante la razón y que, a pesar de que todos puedan participar en su descubrimiento, resulta imposible que lo hagan individualmente es lo que hace que la deliberación y la contradicción cobren importancia. Con esa forma de pensar, aunque con unos fundamentos bien distintos, es con la que se construye la práctica parlamentaria que siglo y medio después lleva a Kelsen (1982: 200) a decir que «el parlamentarismo democrático tendrá que presentarse desde posiciones crítico-relativistas. Se trata de un relativismo filosófico que, por partir de la imposibilidad de expresar apriorísticamente valores o verdades absolutas, y, estar dispuesto a considerar el valor de las opiniones contrarias no puede abandonar el método dialéctico a través del cual se sintetizan las tesis contrastantes».

En los años ochenta del siglo pasado la doctrina se hacía eco de una de las paradojas más graves que este modelo para la conformación de la voluntad general tiene: en el Parlamento representativo el debate se desarrolla entre diputados que, por esencia del sistema, no pueden estar sometidos a mandato imperativo. Eso hace que entre los representantes y los representados se produzca un distanciamiento, un alejamiento que lleva al ciudadano común a sentirse fuera de la discusión y las subsiguientes decisiones políticas. De Vega (1985: 57) se preguntaba "¿cómo compaginar el principio auditur et altera parts con la exclusión en el proceso de discusión y decisión parlamentaria de la generalidad de los individuos a los que esas decisiones les van a afectar directamente?» y respondió entonces: con el «reforzamiento de la publicidad». Mediante ella el ciudadano podía ver proyectadas sus propias opiniones en las opiniones mantenidas por los representantes. En la actualidad, con el apoyo de las nuevas tecnologías se podría dar un paso más. Los ciudadanos pueden hacerse presentes en muchos de los procedimientos parlamentarios. No es un disparate abrir un tiempo de información pública y aportación ciudadana en la fase de enmienda de los procedimientos parlamentarios; tampoco sería una locura ofrecer a la ciudadanía un espacio para que, mediante la intermediación de los parlamentarios, pudieran interrogar al Gobierno y sus miembros. En definitiva, sin menoscabo de que estamos y seguiremos estando en un sistema representativo, hoy es posible abrir ventanas para que los representados puedan, aunque tan solo sea limitadamente, participar en los ámbitos de debate y discusión parlamentaria. Además, es 
probable que esa apertura de los debates a los ciudadanos fuera una contribución para romper con el corsé que el modelo de partidos impone y ayudara a acercar más la actividad parlamentaria a las necesidades reales de la ciudadanía.

Una última cuestión relacionada con este tema tiene que ver con la recuperación de la dinámica de un debate que se organice de acuerdo a los principios de contradicción. Como decíamos, en los fundamentos filosóficos de la actividad parlamentaria ilustrada estaba la búsqueda de la verdad mediante la contraposición de las razones singulares. El Parlamento mediatizado por los partidos y los mass media ha diluido esa técnica para el desarrollo de los debates, con sus estrategias de comunicación de argumentos simples y sin matices. Aquí, también, las nuevas tecnologías pueden hacer algunas aportaciones. En todo caso, para corregir esta situación deberíamos ajustarnos más a las ideas que formularon los clásicos de la organización parlamentaria. Bentham, en su Essays on Political Tactics, aportaba algunos principios organizativos: i) toda proposición que se vaya a debatir en la Cámara ha de ser apoyada por algún sujeto parlamentario distinto a su autor; ii) los debates se pueden organizar con dos formatos distintos, uno sin réplica y otro con ella, que es el que debe primar; iii) debe observarse con rigurosidad la unidad de debate; iv) se ha de separar el debate de la emisión del voto; v) se ha de seguir un orden riguroso y predeterminado en el uso de la palabra; vi) se han de excluir los debates con lectura de discursos escritos ${ }^{20}$; vii) todo debate debe ir precedido de la puesta a disposición de los parlamentarios de los documentos necesarios para su información. En particular, los intervinientes en el debate no deben hacer referencia a documentos que previamente no se hayan puesto a disposición de la Cámara.

Como podemos observar, muchas de las buenas prácticas para el desarrollo de un debate contradictorio que ofrece Bentham tienen que ver con el acceso a la información necesaria por parte de los parlamentarios. Idea que introduce el tema que hemos de desarrollar en el siguiente epígrafe: la publicidad en el tiempo de la transparencia.

20 Sobre la necesidad de que los debates parlamentarios sean de viva voz ya Constant nos recordaba que "Cuando los oradores se limitan a leer lo que han escrito en la soledad de sus despachos, no discuten, amplifican; no escuchan, pues lo que oigan no debe cambiar en nada lo que van a decir, simplemente esperan a que acabe el que les precede: no analizan la opinión que el otro defiende, sólo cuentan el tiempo que emplea, y que les parece excesivo. No hay discusión, todos reproducen objeciones que ya han sido refutadas, nadie se ocupa de lo imprevisto, de lo que podría estropear un alegato previamente redactado». Constant (1989: 78). 


\section{UN PARLAMENTO QUE REFUERZA LA PUBLICIDAD CONVIRTIÉNDOLA EN TRANSPARENCIA}

Aunque nadie discute que hoy día la publicidad forma parte de la esencia de la institución parlamentaria, no siempre fue así y en los orígenes del Parlamento inglés tanto las votaciones como las deliberaciones de las Cámaras era común que fueran secretas. La necesidad de proteger a los diputados de las venganzas y arbitrariedades de los monarcas así como de los caprichos y presiones de las masas de Londres configurarían al secreto, junto con los privilegios individuales como instrumentos imprescindibles para la defensa de la soberanía parlamentaria (De Vega García, 1985: 45-46; Zagrebelsky, 1979: 3-26; Constanzo, 1984: 120; May, 1976: 76-82; Bagehot, 2010: 127 y ss; Chastenet, 2012: 139-160).

Sin embargo, esto pronto cambió, y ese mismo Parlamento es el que se apunta a la idea moderna, en el siglo XviI, de que en la sociedad de la razón todo debe ser legible y mensurable. En Inglaterra, la publicación en 1610 por parte del Gobierno del rey de un balance de los ingresos y los gastos del presupuesto marcaría el inicio de la publicidad parlamentaria. Siguiendo esos primeros pasos, en 1644 se creó en la Cámara de los Comunes un principio de Comisión de cuentas que ampliaba la publicidad del presupuesto real y que fue poco a poco, durante todo el siglo XVII, adquiriendo más competencias de inspección y control. Por ello, como recuerda Rosanvallon (2015:199 y ss.) cuando narra estos primeros momentos de la publicidad parlamentaria, si Inglaterra fue el laboratorio de la accountability, en Francia se publicó el primer manifiesto donde se teorizaba sobre las virtudes de la transparencia financiera, demostrando, una vez más en el desarrollo de la historia constitucional, la contraposición entre empirismo anglosajón y racionalismo continental. Necker publicó en 1781 un Compte rendu au Roi (Informe al rey) que tuvo un gran impacto en toda Europa, en el que se recogían por primera vez todos los datos que permitían evaluar el presupuesto del Estado.

La consolidación de esta apertura y publicidad, particularmente para el debate y conocimiento de los presupuestos, cuaja definitivamente en la consolidación de los Gobiernos representativos del siglo xIx. El control parlamentario de este modelo requería, para que fuera efectivo, la publicidad del trabajo de los representantes de la nación. Aquí, nuevamente, Bentham hace una de las primeras aportaciones doctrinales y prácticas a la publicidad parlamentaria; muestra ya las virtudes que esta puede aportar para el fortalecimiento de la democracia representativa: i) la publicidad tiene un enorme valor para la pedagogía política; mediante la publicidad parlamentaria las ideas y los proyectos buenos se difunden y penetran en la sociedad, mientras que los prejuicios y las supercherías 
pueden ser combatidos y aniquilados; ii) la publicidad es el mejor instrumento para combatir la corrupción y la arbitrariedad, el poder se siente observado y limitado por el ojo público; iii) la publicidad contribuye a romper, en parte, la distancia que separa en los sistemas representativos al representante y los representados, de manera que esta forma se contribuye a que los ciudadanos puedan interiorizar las medidas legislativas como propias; vi) finalmente, Bentham también entendía que la publicidad contribuía al buen funcionamiento del sistema electoral (Bentham, 1991: 71 y ss.; Aranda Álvarez, 2013b: 221).

El principio de publicidad ha adquirido un especial protagonismo en los últimos tiempos. La sociedad de la globalización, el mundo de la información y un desarrollo tecnológico que facilita el acceso a ella han puesto de nuevo a la publicidad en el centro del debate político y social. Un debate que aunque tiene nuevos vectores a tener en cuenta, no es nuevo, como ya hemos visto en páginas anteriores. Podemos observar que los principios sobre la publicidad que utilizaba Bentham siguen estando vigentes. Sin que ello nos impida poder hacer alguna matización que apuntaremos más adelante.

El término "transparencia» aporta uno de esos nuevos vectores que hacen oportuno que reformulemos nuestros conocimientos. En el ámbito parlamentario la publicidad clásica se desarrolla, tal y como hemos visto más atrás, en torno a las cuestiones financieras y presupuestarias. En la sociedad democrática contemporánea se reclama de todos los ámbitos de interés público. El ya citado Rosanvallon (2015: 212) lo expone gráficamente cuando dice que los ciudadanos hoy día reclaman la apertura de todas las «cajas negras». En un mundo en el que es posible la total apertura y acceso a la información, la cuestión no es solo tener dicha información, sino, como explica, la legibilidad de la misma información: que la forma de poner a disposición de los ciudadanos la información sea fácil y comprensible. No debemos confundir información con sobreexposición, que en muchos casos lo que provoca es confusión, complejidad y, con ello, nuevas formas de ocultamiento. T. R. Fernández, en su comparecencia ante la Comisión constitucional del Congreso de los Diputados en la tramitación de la ley de transparencia, decía que no se debe confundir dar información con que la Administración sea transparente y, para ejemplificarlo, ponía el ejemplo de los Presupuestos Generales del Estado que se "cuelgan" en la red, se publicitan en el BOE pero respecto a los cuales para muchos ciudadanos su contenido sigue siendo oscuro, no porque no sean públicos sino porque no son accesibles para aquellas personas que no tengan conocimientos de economía y contabilidad ${ }^{21}$. Con un planteamiento más

21 Diario de Sesiones del Congreso de los Diputados. Comisión Constitucional. X Legislatura. Sesión número 10 celebrada el 12 de febrero de 2013. Núm. 253. 
general, pero que aporta otro sutil matiz a tener en cuenta, Innerarity (2013:96) ha dicho que «es la opacidad y no la falta de transparencia lo que más empobrece las democracias. Obsesionarse con la transparencia descuidando todo lo demás equivale a equivocarse en el foco de atención. Nuestro gran enemigo no es el secreto, la ocultación o la intriga, sino la banalidad [...] la democracia está hoy más empobrecida por los discursos que no dicen nada que por el ocultamiento expreso de información».

En esta nueva fase de la publicidad la intervención del Parlamento también debe verse afectada. Como recordaba Bentham, en la primera fase, la publicidad parlamentaria consistía en que los diputados tuvieran acceso a la información, a la que seguía la posibilidad de que estos pudieran poner su mirada sobre el Gobierno y su actividad y de esta forma se facilitara el control. Ahora lo que se requiere es que la información accesible y comprensible esté a disposición de todos, que los ciudadanos puedan mirar al Parlamento y el trabajo de sus parlamentarios y, por supuesto, conozcan la acción del Gobierno. En esta nueva fase el objetivo es el derecho a saber que está destinado a ampliar el concepto de ciudadanía ${ }^{22}$. Para Rosanvallon (2015: 214) ese derecho tiene dos caras: la que lo liga a la noción de gobierno abierto y la que lo liga a la idea de sociedad legible. Aunque esta remozada óptica de la publicidad supone un importante progreso, quizás no sea tanto como para decir, como hace el autor, que «[...] se trata de una expresión contemporánea de la democracia directa». Más bien es una nueva oportunidad para mejorar las condiciones en las que se desarrolla la función representativa ${ }^{23}$.

Sin menoscabo de todo lo anteriormente dicho, hemos de hacer una pequeña puntualización para indicar que los «excesos de publicidad», en algunos casos, pueden llegar a ser contraproducentes para la deliberación parlamentaria. Como ha seńalado Chambers, en un contexto de «lucha» entre partidos, la publicidad puede ser un incentivo para una retórica plebiscitaria —una retórica donde lo único que se pretende con el discurso es quedar mejor ante los medios que el adversario político y donde existe nula voluntad de negociación y acuerdo- (Chambers, 2004: 389-410; Bitonte y Dumm, 2007: 169-195). Por ello, en ciertos procedimientos parlamentarios — por

22 Sobre el derecho a la información como derecho fundamental véase Aranda Álvarez (2013b: 224-227).

23 La profesora García-Escudero nos recuerda que aunque en estos tiempos se pueda considerar una afirmación políticamente incorrecta, «el Parlamento es la institución más transparente en la toma de decisiones». Lo que no le impide reconocer que el Estado de partidos y la extraparlamentarización de las negociaciones desvirtúan esa transparencia. García-Escudero Márquez, (2015: 194). 
ejemplo, legislativos - u órganos — por ejemplo, subcomisiones — no se debe despreciar la posibilidad de que las negociaciones entre los representantes se desarrollen sin la presencia de los medios de comunicación — por ejemplo, fase de ponencia en la actividad legislativa—.

\section{UN PARLAMENTO QUE EXTIENDE LA COLABORACIÓN A OTROS ÓRGANOS DEL ESTADO E INSTITUCIONES}

La esencia del parlamentarismo siempre ha estado en la colaboración entre órganos del Estado y, en particular, entre el Parlamento y el Gobierno ${ }^{24}$. A lo largo de la historia de esta forma de gobierno hemos tenido distintos ejemplos de protagonismo de uno $\mathrm{u}$ otros de estos dos poderes - Gobierno de Westminster, Gobierno de Asamblea- ${ }^{25}$. Desde la segunda mitad del siglo xx se ha ido generalizando en muchos países de Europa un parlamentarismo presidencializado destinado a prevenir los problemas de inestabilidad gubernamental tan propios de los regímenes de asamblea. La técnica para conseguir este modelo va desde la imposibilidad práctica de censurar a los ministros del Gobierno hasta la regulación de la llamada «moción de censura constructiva» o el establecimiento de sistemas electorales que favorezcan la conformación de mayorías política claras. Como todo el mundo sabe, nuestro parlamentarismo es un buen ejemplo de este modelo que, además, se ha visto reforzado por el ingente protagonismo que se ha dado a los partidos políticos. El resultado, en nuestro caso, es que se ha sobrepasado el objetivo de proteger al Ejecutivo garantizando la estabilidad de Gobierno y el Parlamento y los parlamentarios se presentan como meros «instrumentos» en manos del poder del Ejecutivo, que es quien determina «qué se hace», "quién lo hace» y «cómo se hace» en la vida parlamentaria.

Aunque las propuestas para la colaboración entre el Parlamento y el Gobierno no van a cambiar el desequilibrio antes citado, lo cierto es que pueden ayudar a avanzar en la supervisión y el control parlamentario y, con ello, en la posición del legislativo en esa tensa relación. Las posibilidades para ello son muchas. Dado que este trabajo solo pretende mostrar la necesidad de desarrollar más este principio de colaboración, nos limitamos a presentar algunos ejemplos de colaboración con el Ejecutivo u otras instituciones que, de implementarse bien, podrían ser una muy buena práctica.

24 Relación que tiene su origen en el modelo de «Gobierno de gabinete» propio del modelo británico y que tan detalladamente analizó Fraga Iribarne (1960: 123-213).

25 Sobre los distintos tipos de gobierno en la democracia constitucional véase Loewenstein, (1986: 89-148). 
El primero de esos ejemplos es el caso de la Oficina Presupuestaria de las Cortes Generales. Aunque pueda ser un poco tedioso, merece la pena seguir la regulación. De acuerdo con el preámbulo de la Ley 37/2010, por la que se crea la Oficina de las Cortes Generales, «la creación de dicha Oficina obedece a la necesidad de articular en el seno de las Cámaras un mecanismo eficaz de asesoramiento técnico en materia de seguimiento y control de la ejecución de los Presupuestos Generales del Estado y sobre aquellos aspectos que tengan repercusión en los ingresos y gastos públicos, instrumento inspirado en los principios de independencia, objetividad y transparencia que se pone al alcance de los Diputados y Senadores». Pues bien, para la realización de esta actividad el art. 4 de la Ley establece que «el Gobierno remitirá a la Oficina Presupuestaria de las Cortes Generales, para el cumplimiento de sus funciones, información periódica [...]. La Oficina Presupuestaria de las Cortes Generales dispondrá de acceso a las bases de información contable y presupuestaria de la Administración General del Estado, incluido el sector público empresarial y las Entidades Gestoras y Servicios Comunes de la Seguridad Social, de forma directa o mediante petición a los responsables directos de su tratamiento. En particular, podrá acordarse la creación de un canal de información específico y directo entre la Oficina Presupuestaria de las Cortes Generales y los servicios de información, coordinación y programación presupuestaria del Ministerio de Economía y Hacienda». La Resolución de las Mesas del Congreso de los Diputados y del Senado, de 19 de julio de 2011, por la que se regula la composición y funcionamiento de la Oficina Presupuestaria de las Cortes Generales establece, en su art. 10, que a «los efectos previstos en el artículo cuatro 3 de la Ley 37/2010, la Secretaría General hará las gestiones precisas con la Administración General del Estado y, en particular, con los servicios de información, coordinación y programación presupuestaria del Ministerio de Economía y Hacienda para firmar los acuerdos pertinentes que faciliten el acceso a sus bases de información contable y presupuestaria incluido el sector público empresarial y las entidades gestoras y servicios comunes de la Seguridad Social. En concreto, se procurará el acceso al Sistema de Información Contable (SIC)». La previsión de este art. 10 de la citada resolución ha dado lugar al Convenio de colaboración entre la Oficina Presupuestaria de las Cortes Generales y la Vicepresidencia del Gobierno y Ministerio de Presidencia de 4 de diciembre de 2014 por el cual el Ministerio de Presidencia facilita el acceso a la OPCG adscrita a la Secretaría General del Congreso de los Diputados, a los servicios de suministro en línea de datos de seguimiento presupuestario gestionados por la Inspección General de la Administración del Estado (IGAE) y la Inspección General de la Seguridad Social (IGSS). Como se decía más arriba, si esta estructura de colaboración 
funciona adecuadamente, seguro que puede ser un buen ejemplo de cooperación entre Parlamento y Gobierno. Ahora quedaría, aunque no es objeto de este trabajo, hacer un seguimiento de esta colaboración para saber si es efectiva; de entrada, que el Convenio de colaboración entre el Gobierno y las Cortes Generales para el suministro en línea de datos presupuestarios haya tardado cuatro años en formalizarse no es para ser optimista ${ }^{26}$.

Un segundo ejemplo de colaboración parlamentaria es el que se desarrolla desde la entrada en vigor del Tratado de la Unión Europea (TUE) y el Protocolo núm. 2 sobre la aplicación de los principios de subsidiariedad y proporcionalidad entre los órganos legislativos de la Unión y los Parlamentos nacionales ${ }^{27}$. Para ello, de acuerdo con el art. 49 del TUE, se desarrollará un proceso de cooperación interparlamentaria entre los Parlamentos nacionales y el Parlamento Europeo en los términos del Protocolo n. ${ }^{\circ} 1$ que prevé el intercambio de información y buenas prácticas entre los Parlamentos nacionales y el Parlamento Europeo y entre sus comisiones especializadas, a través de una Conferencia de órganos parlamentarios especializados en asuntos de la Unión (COSAC). El Parlamento Europeo informa regularmente de sus actividades a los Parlamentos nacionales de los Estados miembros, con los que mantiene estrechos vínculos de cooperación mediante reuniones celebradas con regularidad, y apoya activamente dos grandes redes que facilitan la cooperación interparlamentaria: la InterParliamentary EU Information eXchange (IPEX) y el Centro Europeo de Investigación y Documentación Parlamentaria (CEIDP).

Merece la pena seńalar la experiencia IPEX, una plataforma para el intercambio de información entre los Parlamentos nacionales que ofrece información sobre el seguimiento de los asuntos europeos y sobre el control de subsidiariedad. Mediante ella, los Parlamentos nacionales proporcionan directamente la información del control que realizan sobre el cumplimiento de los principios de subsidiariedad y proporcionalidad de las iniciativas legislativas europeas.

Un tercer ejemplo serían las experiencias Red Parlamenta, que es una red de cooperación de los servicios documentales de los Parlamentos autonómicos que dedica una sección de su página al principio de subsidiariedad y proporcionalidad; y la REGPEX, plataforma desarrollada por la Subsidiarity Monitoring Network del Comité de las Regiones de la Unión Europea para el

Una crítica a la implementación de este sistema Giménez Sánchez (2015: 125-142).

27 Sobre la aplicación del principio de subsidiariedad por los parlamentos nacionales, véase Delgado-Iribarren García-Campero (2002); Emiliou (1992); Davies (2006); Aranda Álvarez (2013a). 
apoyo a la participación de las regiones con poderes legislativos en el sistema de alerta temprana. A través de esta plataforma sus miembros obtienen información y expresan su opinión sobre los documentos sometidos a consulta ${ }^{28}$.

Los ejemplos que acabamos de presentar son una pequeña muestra de las oportunidades que las nuevas tecnologías ofrecen para la colaboración entre el Parlamento y otras instituciones. Como se puede comprobar, en estos supuestos se ha transcendido la conformación de páginas web que ofrezcan información pasiva para aquellos que tengan interés en su consulta y estamos ante la creación de herramientas que permiten un trabajo colaborativo entre las instituciones implicadas mejorando sustancialmente el control parlamentario o la participación en la acción legislativa de la UE. Es decir, que con este sistema, y siempre que se ponga en marcha adecuadamente, estaríamos antes instituciones representativas que desarrollan parte de su trabajo «en red».

\section{UN PARLAMENTO QUE RECUPERA EL SENTIDO DE LA RESPONSABILIDAD POLIITICA}

Dirimir la responsabilidad política gubernamental es una de las misiones más tradicionales y que mejor definen la actividad del Parlamento ${ }^{29}$. Sin embargo, en el parlamentarismo racionalizado la responsabilidad política del Gobierno se ha ido diluyendo hasta el punto de que hoy día es muy frecuente oír a portavoces gubernamentales decir que es el electorado quién realmente deduce la responsabilidad de sus actos y que una vez los ciudadanos han ratificado al Gobierno en un proceso electoral, queda saldada cualquier culpa por

28 Véase la página web de la Comisión mixta para la Unión Europea de las Cortes Generales y, en particular, su apartado de información sobre el control del principio de subsidiariedad: http://www.congreso.es/portal/page/portal/Congreso/Congreso/ CongresoUE. También http://www.ipex.eu/IPEXL-WEB/search.do, http://www. redparlamenta.com/tablon-de-anuncios/principio-de-subsidiariedad/regulacion-en-los-parlamentos-del-principio-de-subsidiariedad y http://www.redparlamenta. $\mathrm{com} /$ tablon-de-anuncios/principio-de-subsidiariedad/regulacion-en-losparlamentos-del-principio-de-subsidiariedad.

29 Como dijera Stuart Mill (1985: 65), «la verdadera misión de una Asamblea representativa no es gobernar, porque es radicalmente impropia para ello, sino vigilar a intervenir el Gobierno; poner luz a todos los actos; exigir su exposición, y justificación, cuando le parezca oportuno; condenarlos si son censurables; arrojar de su pues a los hombres que compongan el Gobierno si abusan de su empleo o lo ven contrariamente a la voluntad manifiesta de la nación, y nombrar a sus sucesores, sea expresa, sea virtualmente». 
corrupción o mal gobierno. Entender la responsabilidad en estos términos - lógica mecanicista de imputación - supone haber perdido de vista que este instrumento parlamentario, como la representación, participa de otra lógica bien distinta: la ficción democrática. Al igual que en la representación aceptamos que lo que hace un número reducido de personas en las Cámaras expresa la voluntad general del pueblo, se debe asumir que el control político parlamentario es la forma de romper la impunidad de los gobernantes y la manera de que los ciudadanos sientan que un mal gobierno conlleva consecuencias más allá de la penales ${ }^{30}$. Entender así la responsabilidad, supone que «cuando un acontecimiento de importancia real o simbólica conmueve profundamente a la opinión, la dimisión de un ministro en cuanto figura responsable devuelve sentido y nobleza a la acción política, así como a la persona en cuestión, al igual que al servicio público al que ella ésta ligada. Permite a un hombre [...] hacerse cargo de los pecados de su administración en circunstancias graves, efectuando de tal modo una obra de purificación democrática» (Rosanvallon, 2015: 243-244).

Pues bien, entre el pragmatismo de la responsabilidad diferida in todo al veredicto de los ciudadanos y la responsabilidad como compromiso personal del gobernante para que con la asunción de la culpa política se mantenga la confianza de los ciudadanos en el sistema, podemos buscar una zona intermedia en la que mediante el reforzamiento de los instrumentos de control parlamentario a los gobernantes les sea difícil librarse de responder de sus actos políticos censurables. Hasta ahora, al menos en los sistemas parlamentarios racionalizados, el control de la responsabilidad se ha asociado a los instrumentos que podían poner en cuestión la posesión del poder; en concreto, los instrumentos que sirven para la dimisión del Gobierno ${ }^{31}$. Sin embargo, no se ha prestado importancia a los instrumentos que pueden servir para la validación del ejercicio del poder; en concreto, en aquellos medios mediante los cuales el Gobierno debe dar cuenta de sus propios actos (accountability). Aunque esta perspectiva de la responsabilidad política es la más clásica ${ }^{32}$, durante mucho

30 García Roca (2016: 65) ha dicho, con buen criterio que «el concepto de control debe ligarse — de forma intermedia - a dos cosas: la fiscalización de la acción del gobierno y la responsabilidad política. No obstante, admitiremos que la función de control se sustancia en actividades y actos parlamentarios con muy distinta forma y contenido». Sobre el control parlamentario en sentido general véase Rubio Llorente (1997: 205-228).

31 Sobre el concepto de control, véase por todos: García Morillo (1985: 41 y ss); Aragón Reyes, (1995: 154 y ss); Rubio Llorente, (1997: 205-222).

32 Stuart Mill, (1985: 54 y ss). Un estudio detallado de esta tesis «clásica» del control puede verse en Bustos (2001). 
tiempo ha quedado tan devaluada que en muchos casos lo más que se ha hecho es establecer instrumentos parlamentarios para que la oposición pueda reclamar información de los gobernantes (por ejemplo, preguntas, interpelaciones o comparecencias gubernamentales). Hasta tal punto ha sido así que no han faltado posiciones doctrinales que consideran que dichos instrumentos no son más que mecanismos de información parlamentaria o, en el mejor de los casos, instrumentos de control sin sanción (Llop Ribalta, 2012: 66 y 67).

Sin embargo, como nos recuerda García de Enterría, desde Locke se ha concebido la relación entre gobernantes y gobernados en torno al concepto de trust, fiducia para una gestión o fin concreto. «Lo esencial del trust en la cultura jurídica anglosajona es la formulación de la idea de confianza, la cual (como ocurre en el mandato de los Derechos romanizados) no se entrega de una vez por toda, sino que ha de mantenerse viva de forma constante y desde la cual pueden dirigirse instrucciones al fiduciario y, eventualmente revocarlo». Por ello, sigue diciendo el profesor «[...] la falta de confianza en la clase política es la expresión de que el pueblo se siente, literalmente, alienado por un poder extraño, que no es capaz de interiorizar o sentir como suyo y cuya actuación no considera que se realiza en su propio beneficio, sino en el de los propios titulares de la gestión. Supone, así, una ruptura de la relación de trust, confianza o fiducia y, con ello, de la legitimidad del sistema mismo, la más grave, pues, de las deficiencia imaginables en una democracia» (García de Enterría, 1995 y 1989).

En este sentido, la sociedad de la información y las nuevas tecnologías puede ofrecer buenas oportunidades y, al igual que en las normas sobre el buen gobierno se establecen mecanismos de dación de cuentas, se podrían explorar nuevos instrumentos parlamentarios para el control del Gobierno. Para Rosanvallon (2015: 245 y ss.), esos nuevos instrumentos deben articularse en torno a tres grandes líneas de actuación: i) presentación de una contabilidad, ii) justificación de los actos realizados o decisiones tomadas, y iii) evaluación de las políticas implementadas.

i) La presentación de una contabilidad se hace efectiva mediante la accountability o rendición de cuentas. Para ello es necesario que los datos presupuestarios se pongan a disposición del Parlamento cada vez de forma más detallada, sistemática y con toda claridad y posibilidad de comprensión para un ciudadano medio. En nuestro Parlamento la puesta en marcha de la Oficina Presupuestaria iría en esta línea; ahora bien, parece claro que peca de notables deficiencias para que la información sobre los presupuestos y su ejecución quede sin restricciones en manos de los parlamentarios. 
ii) La responsabilidad justificación. Tradicionalmente, la responsabilidad política ha supuesto una relación entre el Gobierno y la oposición. En esta relación tienen una importancia destacada los grupos parlamentarios de la oposición, que son los que de verdad ostentan interés en hacer al Ejecutivo responsable de sus actos. Desde luego, en el funcionamiento de nuestro Parlamento salta a la vista la necesidad de reforzar la posición de la oposición, no han faltado ya autores que se pronuncian por la constitucionalización o, al menos, reglamentación del estatuto de la oposición ${ }^{33}$. Pero hoy día también aquí se podría ir un poco más allá y se pueden explorar vías para que los ciudadanos y los grupos puedan participar en algunos de los medios de control (por ejemplo presentando preguntas y reclamando información al Gobierno y sus miembros cuando comparecen en comisiones, aportando información en las comisiones de investigación o estudio, etc.).

iii) La responsabilidad evaluación. Supone, como en la rendición de cuentas, que en el ámbito parlamentario se abran espacios efectivos para la evaluación de las políticas públicas. Evaluación que ofrezca la oportunidad de comprobar no solo si se han gestionado correctamente los recursos públicos sino si se han conseguido cumplir los objetivos previstos. Somos conscientes de que este tipo de inspección tiene una notable complejidad y en algunos casos requeriría de órganos técnicos que elaborasen los estudios y análisis previos a su supervisión parlamentaria. Recientemente se han creado algunos de estos organismos - Autoridad Independiente de Responsabilidad Fiscal o Consejo de Transparencia y Buen Gobierno-, pero lo curioso es que tanto en su conformación como en su funcionamiento se han vinculado al Gobierno, que es justamente al que deben inspeccionar.

\section{UN PARLAMENTO QUE SE ABRE A LA PARTICIPACIÓN DIRECTA DE LOS CIUDADANOS}

Uno de los motivos por los que se habla de la necesidad de un «Parlamento abierto" es porque muchos ciudadanos no se sienten representados por aquellos a los que han elegidos en las elecciones. Además, tienen la impresión

33 El profesor Garrorena Morales (2014: 201-205) ha dicho que la actividad de control parlamentario se debería reorganizar desde el reconocimiento, incluso constitucionalmente, del estatuto de la oposición. 
de que todas sus reclamaciones, cuando llegan al Parlamento, se disuelven en un mar de negociaciones e intereses contrapuestos. Para combatir esta situación se especula con las posibilidades que las TIC pueden ofrecer para tener un Parlamento más abierto a los ciudadanos y sus reclamaciones.

El problema es que las formas de participación directa de los ciudadanos en el ámbito parlamentario siempre han estado sometidas a fuertes críticas: para unos, la democracia representativa supone que aquellos a los que se ha elegido para dicha misión son los que tienen el «monopolio de hablar por la nación o el pueblo»; para otros, porque hay que evitar a toda costa instrumentos parlamentarios que sean utilizados para erigir los anhelos personales en decisión política y de esa manera sustituir el sistema representativo por la «anarquía democrática». Frente a estas posiciones se encuentran los que entienden que poner en marcha canales de participación de los ciudadanos en la vida parlamentaria supondrá un refuerzo en la legitimidad de las decisiones que se toman, además de enriquecer los debates con la integración de la opinión de las personas que están más inmediatamente afectadas (Aguiar de Luque, 2001: 7).

Hasta ahora, cuando se hablaba de participación en las funciones parlamentarias se estaba pensando en la integración de las minorías y en que ninguno de los miembros de la Cámara quedara excluido del debate. En la actualidad se piensa que, además de ese objetivo, hay que tratar de abrir instrumentos de participación pública con el objeto de acercar el Parlamento a la sociedad. En este sentido, la Conferencia de Presidentes de Parlamentos Autonómicos (COPREPA) reunida el día 31 de enero de 2015 aprobó una declaración institucional en la que manifestó la necesidad de que los Parlamentos Autonómicos «deben [...] situarse en la vanguardia en la apertura de nuevos cauces de participación como la e-Democracia, con el compromiso de continuar con ese proceso de apertura a la ciudadanía, para que pueda conocer mejor el funcionamiento interno de las Cámaras». Una buena iniciativa en este sentido fue la propuesta de «Escaño 351» presentada por el Grupo Parlamentario Socialista con el objetivo de habilitar un procedimiento para que los ciudadanos puedan defender personalmente sus reclamaciones en sede parlamentaria. Para ello, se reformaría la Comisión de peticiones convirtiéndola en la «Comisión permanente y de participación ciudadana». Por lo tanto, cuando se habla de reforzar la participación ciudadana en la vida parlamentaria una de las cuestiones a resolver es la de las distintas posibilidades para esa mayor participación.

Vela Navarro-Rubio (2015: 384-386), cuando se ocupa de la participación pública en las funciones parlamentarias, divide esos instrumentos en dos grandes grupos: i) herramientas no digitales de participación en los procedimientos 
parlamentarios — audiencia públicas, peticiones, quejas y denuncias, «Tribunos de la plebe» o sesiones de puertas abiertas, iniciativas de movilidad parlamentaria, iniciativas legislativas populares y organismos especiales de participación en los parlamentos-; ii) herramientas de participación que producen la participación ciudadana en el parlamento mediante las TIC — «Encuentros abiertos digitales» en el Congreso de los EE.UU., los debates públicos temáticos del Parlamento británico, la iniciativa ciudadana europea, las plataformas digitales de participación en el Parlamento, el «Senado virtual chileno», el proyecto e-democracia de la Cámara de diputados de Brasil-.

Todas las vías y ejemplos de participación apuntados demuestran que ya contamos con una importante experiencia - por ejemplo, el desarrollo de estos instrumentos por parte de muchos de los Parlamentos autonómicos españoles: País Vasco, Cataluña, Andalucía, Valencia, Extremadura, etc.que podría servir para evaluar la participación ciudadana en el Parlamento y establecer los términos en los que se debe producir. El autor citado, una vez realizado un exhaustivo estudio de estos medios de participación ciudadana a través de las TIC en los Parlamentos, saca algunas conclusiones de las condiciones en las que se deben producir que pasamos a reproducir: i) la participación ciudadana no puede ser vinculante para el Parlamento, ii) el Parlamento debe tutelar el proceso de participación, que ha de llevarse a cabo de forma estructurada y organizada, iii) el proceso de participación debe ser transparente en todas sus fases, iv) la promoción del proceso de participación debe hacerse de forma enfocada y v) la tecnología aplicada a la participación en el ámbito parlamentario ha de cumplir unos requisitos de accesibilidad, entendible, intuitiva, ajustada al contexto social, político y organizativo de los participantes y renovable (Vela Navarro-Rubio, 2015: 387-414).

De lo visto hasta aquí y de la experiencia práctica con la que contamos se puede llegar a la conclusión de que la participación ciudadana no pretende sustituir a la institución parlamentaria; muy al contrario, desde una lógica de democracia participativa procura aprovechar las oportunidades que las nuevas tecnologías ofrecen para mejorar la democracia representativa y romper el distanciamiento entre la institución y los ciudadanos. Como ha señalado Rubio Núñez (2014: 413), «[...] no se trata de generar apariencia de participación, ni de prometer a los ciudadanos un papel decisorio que no les corresponde en el diseño actual de la democracia, se trata implementar procedimientos ofreciendo espacios de deliberación democrática de carácter público y abiertos». En definitiva, reforzar la representación con una mayor participación ciudadana que no es otra cosa que cumplir la previsión del preámbulo de nuestra Constitución cuando establece como objetivo «establecer una sociedad democrática avanzada». 


\section{CONCLUSIONES}

La innovación en tecnológica e información siempre ha contribuido a la modernización del Parlamento. Tanto la organización como el funcionamiento parlamentario se han ido ajustado a las posibilidades que los recursos técnicos y de información de cada momento ofrecían: los medios de transporte condicionaban la programación de las sesiones parlamentarias; la imprenta y la técnica taquigráfica, la recogida de sus debates; los medios de comunicación impresos, la radio y la televisión, la publicidad de su trabajo, y así hasta nuestros días. Sin embargo, esos cambios no han variado su objetivo último: construir una institución mediante la cual hacer presente un sujeto político abstracto como es el pueblo.

La incorporación de las TIC al Parlamento debemos verla, fundamentalmente, en ese proceso continuado de transformación de sus técnicas de organización y funcionamiento. Desde nuestro punto de vista esta posición no resta importancia a los efectos de las TIC en la institución parlamentaria, sino que las considera como instrumentos que sirven para fortalecer algunos de los principios que caracterizan al Parlamento: representación, deliberación, colaboración, publicidad o participación. Como decíamos al principio, esto no es poca cosa, estos recursos inciden directamente en los principios esenciales de la institución parlamentaria. Muestra de ello es que tanto la representación política como la legitimación de órganos del Estado pueden mejorar notablemente con la incorporación de las TIC al Parlamento: en el primer caso, porque es más fácil integrar los intereses de los ciudadanos; en el segundo, porque la publicitación de los procedimientos de designación sirven para mejorar el control y la inspección sobre los candidatos.

El avance en la representación y la legitimación está unido al progreso que en el Parlamento se haga con las TIC en colaboración, control, transparencia y participación. Seguramente, trabajando en esta línea podamos empezar a corregir las patologías de nuestro parlamentarismo hasta el punto de quitar la razón a aquellos que, como Carl Schmitt (2008: 22-23), decían que debíamos perder la fe en el Parlamento puesto que «la publicidad y la discusión», que para él eran los dos grandes principios de funcionamiento de la institución, «se han convertido, con la dinámica misma del funcionamiento parlamentario, en una vacía y fútil formalidad, el Parlamento, tal y como se ha desarrollado en el siglo xIx, ha perdido su anterior fundamento y sentido». Como hemos visto en los apartados correspondientes de este trabajo, estos principios se están viendo, o podrían verse, notablemente mejorados en sus objetivos con la nueva tecnología de la información y comunicación. En definitiva, las TIC contribuyen a la mejora en la aplicación de los principios y las 
funciones del Parlamento sin que ello suponga transformar el objetivo último de la institución: hacer presente al pueblo.

\section{Bibliografía}

Aguiar de Luque, L. (2001). El impacto de las nuevas tecnologías sobre el principio de representación: ¿¿Democracia directa y democracia representativa? En II Jornadas Parlamentarias de la Asamblea de Madrid. Parlamento y nuevas tecnologías (pp. 5-34). Madrid. Tecnos.

Aragón Reyes, M. (1995). Constitución y control del poder. Buenos Aires. Ediciones Ciudad Argentina.

Aranda Álvarez, E. (2013a). La alerta temprana en el procedimiento legislativo de la Unión Europea. Una reflexión sobre su utilidad desde la reciente experiencia espańola. Revista de Derecho Comunitario Europeo, 44, 101-153.

- (2013b). Una reflexión sobre transparencia y buen gobierno. Cuadernos Manuel Giménez Abad, 5, 214-230.

— (2015). La reducción de parlamentarios y la modificación del régimen retributivo de los miembros de las Asambleas de las CC.AA. Revista de Derecho Político, 92, 119-164. Disponible en: https://doi.org/10.5944/rdp.92.2015.14423.

Bagehot, W. (2010). La Constitución inglesa. Madrid: Centro de Estudios Políticos y Constitucionales.

Bellamy, C. (2000). Modelling electronic democracy: Towards democratic discourses for an informamation age. En J. Hoff, I. Horrocks y P. Tops (eds.). Democratic Governance and New Techonology (pp. 34-54). Londres: Toutkedge.

Bentham, J. (1991). Tácticas parlamentarias. Madrid: Congreso de los Diputados.

Bitonte, M. E. y Dumm, Z. (2007). El discurso parlamentario: ¿¿diálogo en la torre de Babel? En R. Marafioti (coord.). Parlamentos. Teoría de la argumentación y debate parlamentario (pp. 169-195). Buenos Aires: Biblos.

Burke, E. (1996). Textos políticos. México D. F.: Fondo de Cultura Económica.

- (2008). Discurso a los electores de Bristol. En E. Burke. Revolución y descontento. Selección de escritos. Madrid: Centro de Estudios Políticos y Constitucionales.

Bustos, R. (2001). La responsabilidad politica del Gobierno: ¿realidad o ficción? Madrid: COLEX. Caamaño Domíngez, F. (1991). El mandato parlamentario. Madrid: Congreso de los Diputados.

Cazorla Prieto, L. M. (1985). La oratoria parlamentaria. Madrid: Espasa-Calpe.

Chambers, S. (2004). Behind closed doors: Publicity, secrecy, and the quality of deliberation. The Journal of Political Philosophy, 12 (4), 289-410. Disponible en: https://doi. org/10.1111/j.1467-9760.2004.00206.x.

Chastenet, J. (2012). El Parlamento de Inglaterra. México D. F.: Derecho y Sociedad.

Coleman, S. y Blumler, J. G. (2009). The internet and democratic citizenship: theory, practice and policy. Nueva York: Cambridge University Press. Disponible en: https://doi. org/10.1017/CBO9780511818271.

Constant, B. (1989). Escritos politicos. Madrid: Centro de Estudios Constitucionales. 
Constanzo, P. (1984). Lo scioglimento delle Assemblee Parlamentari. Teoria e prattica dello scioglimento dalle origine al parlamentarismo razionalizzato. Milán: Giuffrè.

Davies, G. (2006). Subsidiarity: The wrong idea, in the wrong place, at the wrong time. Common Market Law Review. 43 (1), 63-84.

Delgado-Iribarren García-Campero, M. (2002). La función de los parlamentos nacionales en la arquitectura europea. En E. García de Enterría y R. Alonso García (coords.). La encrucijada constitucional de la Unión Europea (pp. 365-401). Madrid. Civitas.

De Vega García, P. (1985). El principio de publicidad parlamentaria y su proyección constitucional. Revista de Estudios Políticos, 43, 45-65.

Duverger, M. (1970). Instituciones políticas y derecho constitucional. 5. a edición española. Barcelona: Ariel.

Dworkin, R. (1995). Los derechos en serio. Barcelona: Ariel.

Emiliou, N. (1992). Subsidiarity: an Effective Barrier Against the Enterprisesof Ambition? European Law Review, 17 (5), 383-407.

Fraga Iribarne, M. (1960). El Parlamento Británico. Madrid: Instituto de Estudios Políticos. García de Enterría, E. (1980). Reflexiones sobre la ley y los principios generales del Derecho. Madrid: Civitas.

(1989). La lucha contra las inmunidades del poder. Madrid: Cívitas.

(1995). Democracia, jueces y control de la Administración. Madrid: Civitas.

García-Escudero Márquez, P. (2015). Regeneración del Parlamento, transparencia y participación ciudadana. Revista Teoría y Realidad Constitucional, 36, 171-216.

García Morillo, J. (1985). El control parlamentario del Gobierno en el ordenamiento español. Madrid: Congreso de los Diputados.

García Pelayo, M. (1995). Las transformaciones del Estado contemporáneo. Madrid: Alianza.

García Roca, J. (1999). Cargos públicos representativos. Un estudio del artículo 23.2 de la Constitución. Madrid: Aranzadi.

- (2016). Control parlamentario y convergencia entre presidencialismo y parlamentarismo. Revista Teoría y Realidad Constitucional, 38, 61-99.

Garrorena Morales, A. (2014). Escritos sobre la democracia. La democracia y la crisis de la democracia representativa. Madrid: Centro de Estudios Políticos y Constitucionales.

Giménez Sánchez, I. M. (2015). La nueva oficina presupuestaria de las Cortes Generales. En F. Rubio Llorente, J. Jiménez Campos, J. J. Solozabal Echavarria, P. Biglino Campos y A. Gómez Montoro (coords.). La Constitución politica de España. Estudio en homenaje a Manuel Aragón Reyes (pp. 125-142). Madrid: Centro de Estudios Políticos y Constitucionales.

Greciet García, E. (2012). El Parlamento como problema y como solución. Revista Parlamentaria de la Asamblea de Madrid, 26, 235-298.

Guizot, F. (2009). Historia de los orígenes del gobierno representativo en Europa. Oviedo: KRK Ediciones.

Hagen, M. (2000). Digital Democracy and Political Systems. En K. Hacker y J. van Dijk (eds.). Digital Democracy, Issues of Theory and Practice (pp. 20-45). Londres, Thousand Oaks CA, NuevaDelhi:SagePublications.Disponibleen:https://doi.org/10.4135/9781446218891.n4.

Innerarity, D. (2013). Un mundo de todos y de nadie. Piratas, riesgos y redes en el nuevo desorden global. Madrid: Paidós Estado y Sociedad. 
Kelsen, H. (1977). Esencia y valor de la democracia. Barcelona: Guadarrama. (1982). Il primato del Parlamento. Milán: Giuffrè.

Kriele, M. (1980). Introducción a la teoría del Estado. Buenos Aires: Depalma.

Larenz, K. (1994). Metodología de la Ciencia del Derecho. Barcelona: Ariel.

Lavilla, J. J. (1996). Las fuentes supralegales del Derecho parlamentario. En J. C. da Silva Ochoa (coord.). Instituciones de Derecho Parlamentario I. Las fuentes del Derecho Parlamentario (pp. 49-66). Vitoria: Parlamento Vasco.

Lazer, D., Neblo, M., Esterking, K. y Goldschmidt, K. (2009). On-line town hall meeting: exploring democracy in the 21st century. Washington D. C.: Congressional Management Foundation. Disponible en: http://www.congressfoundation.org/storage/documents/CMF_Pubs/online-town-hall-meetings.pdf.

Lipset, S. M. (1992). Algunos requisitos sociales de la democracia. Desarrollo económico y legitimidad política. En A. Batlle i Rubio (ed.). Diez textos básicos de ciencia polític. (pp. 113-150). Barcelona: Ariel.

Llop Ribalta, M. D. L. (2012). Transparencia, acceso a la información pública y buen gobierno en los Parlamentos. Cuadernos de la Fundación Giménez Abad, 4, 66-83.

Loewenstein, K. (1986). Teoría de la Constitución. Barcelona: Ariel.

Manin, B. (1998). Los principios del Gobierno representativo. Madrid. Alianza.

Masuda, Y. (1984). La sociedad informatizada como sociedad postindustrial. Madrid: Fundesco, Tecnos.

May, E. (1976). Treatis on the Law, Privileges, Proccedings and Usage of Parliament. Londres: Charles Knight.

Pendás García, B. (1996). Otras fuentes. Esbozo de una construcción principialista del Derecho Parlamentario. En J. C. da Silva Ochoa (coord.). Instituciones de Derecho Parlamentario I. Las fuentes del Derecho Parlamentario. Vitoria: Parlamento Vasco.

Pitkin, H. F. (1985). El concepto de representación. Madrid: Centro de Estudios Políticos y Constitucionales.

Porras Nadales, A. (1994). Representación y democracia avanzada. Madrid: Centro de Estudios Políticos y Constitucionales.

Prieto Sanchís, L. (1998). Ley, principios, derechos. Madrid: Instituto de Derechos Humanos «Bartolomé de las Casas»; Universidad Carlos III.

Punset Blanco, R. (2001). Estudios parlamentarios. Madrid: Centro de Estudios Políticos y Constitucionales.

Rosanvallon, P. (2015). El buen Gobierno. Buenos Aires: Manantial.

Rousseau, J. J. (1982). El contrato social. Madrid: Edaf.

Rubio Llorente, F. (1997). El Parlamento y la representación política. En F. Rubio Llorente. La forma del poder. Estudios sobre la Constitución. Madrid: Centro de Estudios Políticos y Constitucionales.

Rubio Núñez, R. (coord.). (2014). Parlamentos abiertos. Tecnología y redes para la democracia. Madrid: Congreso de los Diputados.

Santaolalla López, F. (2010). Problemas de las designaciones parlamentarias en nuestro derecho. En E. Pajares Montolío (coord.). Procedimientos de designación parlamentaria de cargos públicos (pp. 13-54). Madrid: Centro de Estudios Políticos y Constitucionales.

Sartori, G. (1998). Homo videns. La sociedad teledirigida. Madrid: Taurus. 
- (1999). Elementos de teoría politica. Madrid: Alianza Editorial.

(2016). Ingeniería constitucional y comparada. México D. F.: Fondo de Cultura Económica.

Schmitt, C. (2008). Los fundamentos histórico-espirituales del parlamentarismo en su situación actual. Madrid: Tecnos.

Stuart Mill, J. (1985). Del Gobierno representativo. Madrid: Tecnos.

Toffler, A. (1989). La tercera ola. Barcelona: Plaza y Janés.

Tribe, K. H. (1991). The Constitution in Cyberspace. The Humanist, 5.

Tudela Aranda, J. (2008). El Parlamento necesario. Parlamento y democracia en el siglo XXI. Madrid: Congreso de los Diputados.

Van Dijk, J. A. G. M. (2013). Digital democracy: Vision and reality. Disponible en: https:// www.utwente.nl/en/bms/vandijk/research/itv/itv_plaatje/Digital\%20Democracy\%20Vision\%20and\%20Reality.pdf.

Vela Navarro-Rubio, R. (2015). El Parlamento abierto. La influencia de la tecnología en la evolución de la institución parlamentaria [tesis doctoral]. Universidad Complutense de Madrid.

Zagrebelsky, G. (1979). Le immuintà parlamentari. Natura e limiti di una garanzia costituzionale. Turín: Einaudi. 